\title{
Adult Patients' Satisfaction with Inpatient Nursing Care and Associated Factors in an Ethiopian Referral Hospital, Northeast, Ethiopia
}

\author{
Kokeb Haile Eyasu, ${ }^{1}$ Akilew Awoke Adane, ${ }^{2}$ Fisseha Zewdu Amdie, \\ Tesfaye Bisenebit Getahun, ${ }^{3}$ and Mulunesh Abuhay Biwota ${ }^{4}$ \\ ${ }^{1}$ School of Nursing, University of Gondar, P.O. Box 196, Gondar, Ethiopia \\ ${ }^{2}$ Department of Epidemiology and Biostatistics, University of Gondar, P.O. Box 196, Gondar, Ethiopia \\ ${ }^{3}$ Department of Gynecology and Obstetrics, Debre Markos Referral Hospital, Debre Markos, Ethiopia \\ ${ }^{4}$ Department of Midwifery, University of Gondar, P.O. Box 196, Gondar, Ethiopia \\ Correspondence should be addressed to Fisseha Zewdu Amdie; fishomafi2@gmail.com
}

Received 15 March 2016; Revised 10 May 2016; Accepted 15 May 2016

Academic Editor: Jenny M. Wilkinson

Copyright (C) 2016 Kokeb Haile Eyasu et al. This is an open access article distributed under the Creative Commons Attribution License, which permits unrestricted use, distribution, and reproduction in any medium, provided the original work is properly cited.

\begin{abstract}
Introduction. Patient satisfaction with nursing care is considered as an important factor in explaining patients' perceptions of service quality. Care assessed to be high quality according to clinical, economic, or other provider-defined criteria is far from ideal if as a result of that care the patient is unhappy or dissatisfied. Objective. The aim of this study was to assess adult patients' satisfaction with inpatient nursing care and associated factors in Dessie Referral Hospital, Northeast Ethiopia. Methods. Institution based quantitative cross-sectional study was conducted among patients admitted in medical, surgical, orthopedics, gynecology, and ophthalmology wards of the hospital from March 24 to April 30, 2013. All admitted patients who stayed in the study wards for at least two days during the data collection time were interviewed. Newcastle Satisfaction with Nursing Scale questionnaire was used to collect the data and was analyzed using SPSS version 20 . Odds ratios with their $95 \%$ confidence intervals and $p$ values in a multiple logistic regression were used to identify factors associated with patient satisfaction with nursing care. Result. The overall patient satisfaction was 52.5\%. Respondents' sex, age, admission ward, self-reported health status, and class of admission were the variables significantly associated with patient satisfaction with nursing care. Conclusion and Recommendation. The rate of patient satisfaction with nursing care was found to be low in this study. Being female, younger age group (18-30 years), good self-reported current health status, being admitted in ophthalmology ward, and first class of admission were significantly associated with better patient satisfaction with nursing care. In-service training programs for nurses, with special emphasis on communication skills, are recommended.
\end{abstract}

\section{Background}

Healthcare situation is fast changing globally. Patient satisfaction is one of the established standards to evaluate achievement of the services being provided in the hospitals. For healthcare organization to be successful monitored clients view is a simple but important approach to assess and improve their performance [1].

Patient satisfaction can be described as a healthcare recipient's reaction to several aspects of their service experience. It is related to perception of the outcome of care and the extent to which it meets patient expectations. Patients thereby evaluate the healthcare services as well as the providers from their own subjective point of view [2,3]. Conceptually, patient satisfaction has been defined as patient's judgment on the quality and goodness of care [4]. Consequently, a dissatisfied patient is not considered psychologically or socially well and thus the goal of nursing has not been attained $[2,5]$.

Patient satisfaction deserves attention not only because it is basically valuable goal, but also because it is a potentially important mediator for a variety of essential outcomes. Satisfied patients may be more adhered with their treatment, 
suggesting that satisfaction is an important component in promoting health and well-being. Satisfaction may also directly affect the economical capability of an institution by affecting consumer choice of health institution [6]. Satisfaction with care has a vital power determining whether a person seeks medical advice, complies with treatment, and maintains a continuing relationship with healthcare providers $[5,7]$.

Of all the healthcare workers, nurses spend much time with the patients. Therefore, the nurse is in a unique position to influence and promote effective consumer relationships [8]. Patient satisfaction with nursing care is considered an important factor in explaining patients' perceptions of service quality [5]. Measurement of patient satisfaction with inpatient care appears to be more important, because the interaction of patient and nursing staff is high in the ward setting and the illness itself affects the attention of nurses [9].

Although patient satisfaction with nursing care is widely searched in the developed countries, lack of studies made it difficult to find research examining patients' satisfaction with nursing care in developing countries such as Ethiopia [5]. Thus, in this study, patient's satisfaction with nursing care and associated factors has been assessed in referral hospital, Northeast Ethiopia.

\section{Methods}

2.1. Study Setting and Participants. An institution based crosssectional study was conducted, from March 24 to April 30, 2013, in Dessie Referral Hospital, Dessie City, Northeast Ethiopia. The hospital has a total of 200 beds; 136 were in adult medical, surgical, orthopedics, gynecology, and ophthalmology wards. There were 6,787 total admitted patients in 2011 and the hospital has 88 nursing staff (15 B.S. nurses and 73 diploma nurses).

2.2. Sample Size and Sampling Procedure. It was assumed that the precision to an acceptable approximation of the population has been taken to be $95 \%$ with a difference of no more than $5 \%$ from the actual figures in the source population. Sample size was determined by using single population proportion formula and considering $67 \%$ of overall satisfaction rate from a cross-sectional study done in Addis Ababa [5] and adding 10\% possible nonresponse rate during the actual data collection makes the final sample size 374 . But by taking the patient flow in the previous three consecutive months before the study period it was found that on average 400 patients were admitted per month so it was decided to take all admitted patients in the study period.

2.3. Data Collection Procedure. After two days' training, a health officer as supervisor and four grade 12 completed individuals as data collectors were participated in the data collection process. The study participants were asked whether they are able to differentiate nursing staff from other health professionals. If not, the data collectors explained the nurses uniform and the activities of nursing staffs to the participants, to help them to differentiate the nursing staffs before interview.

Data were collected by face to face interviewing using adapted standard questionnaire, Newcastle Satisfaction with
Nursing Scale (NSNS). The NSNS is designed principally to detect differences between wards (hospitals) and patient groups with respect to overall experience of satisfaction with nursing care $[10,11]$.

The questionnaire had three parts; the first about sociodemographic characteristics of the participants, the second satisfaction with nursing care, and the third part about factors associated with patient satisfaction with nursing care. There were 19 items to determine the patients' satisfaction with nursing care under the model. Each item was rated using a five-point Likert-type scale ranging from "1" (not at all satisfied), " 2 " (barely satisfied), “ 3 ” (quite satisfied), “4” (very satisfied), and " 5 " (completely satisfied). The total score was summed and transformed to yield an overall "satisfaction score" of 0 to 100 , where 100 denotes complete satisfaction or highest level of satisfaction with all aspects of nursing care [10].

The English version questionnaire was translated to local language (Amharic) and then back to English by language experts to confirm the consistency of translation.

2.4. Data Processing and Analysis. Data were checked for completeness, cleaned, coded, and entered into EPI-Info version 3.5.3 and then exported to SPSS version 20 for further analysis. Descriptive statistics were computed and bivariate analysis was used primarily to check which variables have association with the dependent variable. Then variables found to have $p$ value of less than 0.2 were entered into multiple logistic regression for controlling the possible effect of confounders. Finally, variables which had statistically significant association were identified on the basis of odds ratio (OR) with 95\% confidence interval (CI).

2.5. Ethical Consideration. Before the field work ethical clearance was obtained from Department of Nursing, University of Gondar. Participation in the study was voluntary and responses of clients were anonymous. A letter of agreement was also attached to the questionnaire to obtain a written consent of each study subject. Participants were guaranteed confidentiality of the information collected; completed questionnaires were stored securely. Participants were also told that their nonparticipation would not have negative effect on their hospital care.

\section{Result}

3.1. Sociodemographic Characteristics of the Respondents. About half of $(50.3 \%)$ study subjects were females and majority of the patients (62.9\%) were married. The mean age of respondents was 38.67 years with SD 14.58. Similarly nearly half $(48.4 \%)$ of them had no formal education, more than half $(57.1 \%)$ were rural dwellers, and majority of them $(65 \%)$ were Muslims. Regarding their occupation, a third (33.7\%) of them were farmers (Table 1).

\subsection{Percentage Distribution of Study Participant's Satisfaction} with Nursing Care by Different Factors. The highest percentage of the study subjects were from medical ward (42.9\%), followed by surgical ward (31.6\%). The length of stay varied from 
TABLE 1: Sociodemographic characteristics of study participants, Dessie Referral Hospital, Northeast Ethiopia $(N=380)$.

\begin{tabular}{|c|c|c|}
\hline Characteristics & Frequency & Percentages \\
\hline \multicolumn{3}{|l|}{ Age (years) } \\
\hline $18-30$ & 142 & 37.4 \\
\hline $31-40$ & 113 & 29.7 \\
\hline $41-50$ & 54 & 14.2 \\
\hline $51-60$ & 31 & 8.2 \\
\hline$\geq 61$ & 40 & 10.5 \\
\hline \multicolumn{3}{|l|}{ Gender } \\
\hline Female & 191 & 50.3 \\
\hline \multicolumn{3}{|l|}{ Religion } \\
\hline Orthodox & 128 & 33.7 \\
\hline Muslim & 247 & 65 \\
\hline Protestant & 5 & 1.3 \\
\hline \multicolumn{3}{|l|}{ Residence } \\
\hline Rural & 217 & 57.1 \\
\hline Urban & 163 & 42.9 \\
\hline \multicolumn{3}{|l|}{ Marital status } \\
\hline Single & 100 & 26.3 \\
\hline Married & 239 & 62.9 \\
\hline Divorced & 19 & 5.0 \\
\hline Widowed & 22 & 5.8 \\
\hline \multicolumn{3}{|l|}{ Education } \\
\hline No formal education & 184 & 48.4 \\
\hline Below 5 th grade & 45 & 11.8 \\
\hline 5 th-8th grade & 94 & 24.7 \\
\hline 9th-12th grade & 29 & 7.6 \\
\hline Certificate and above & 28 & 7.4 \\
\hline \multicolumn{3}{|l|}{ Occupation } \\
\hline Government employee & 27 & 7.1 \\
\hline Nongovernmental employee & 21 & 5.5 \\
\hline Farmer & 128 & 33.7 \\
\hline Merchant & 17 & 4.5 \\
\hline No job & 160 & 42.1 \\
\hline Others & 27 & 7.1 \\
\hline \multicolumn{3}{|l|}{ Income (birr/month) } \\
\hline 150 and below & 190 & 50 \\
\hline $151-600$ & 119 & 31.3 \\
\hline $601-1200$ & 51 & 13.4 \\
\hline 1201 and above & 20 & 5.3 \\
\hline
\end{tabular}

2 to 60 nights and large proportion of patients (95.5\%) stayed in the ward for 2 to 7 nights. Majority of respondents $(79.7 \%)$ were from second class of admission. Similarly, majority (91.3\%) of patents had to pay for the service. Nearly half of respondents $(48.2 \%)$ rated their current health status as good. About a quarter (23.4\%) of respondents had another chronic illness in addition to current health condition and $54.2 \%$ of them responded as nurses were assigned for them (Table 2).
TABle 2: Percentage distribution of study participant's satisfaction with nursing care by different factors, Dessie Referral Hospital, Dessie, Northeast Ethiopia, April, $2013(N=380)$.

\begin{tabular}{|c|c|c|}
\hline Variables & Frequency & Percentages \\
\hline \multicolumn{3}{|l|}{ Admission ward } \\
\hline Medical & 163 & 42.9 \\
\hline Surgical & 120 & 31.6 \\
\hline Orthopedics & 28 & 7.4 \\
\hline Gynecology & 43 & 11.3 \\
\hline Ophthalmology & 26 & 6.8 \\
\hline \multicolumn{3}{|l|}{ Class of admission } \\
\hline First & 78 & 20.3 \\
\hline Second & 302 & 79.7 \\
\hline \multicolumn{3}{|c|}{$\begin{array}{l}\text { Having another disease/chronic illness } \\
\text { in addition to current health problem }\end{array}$} \\
\hline Yes & 89 & 23.4 \\
\hline No & 291 & 76.6 \\
\hline \multicolumn{3}{|c|}{ Length of stay (nights) } \\
\hline 7-14 nights & 344 & 90.5 \\
\hline $8-15$ nights & 28 & 7.4 \\
\hline $16-30$ nights & 3 & 0.8 \\
\hline $31-60$ nights & 5 & 1.3 \\
\hline \multicolumn{3}{|c|}{ History of previous admission } \\
\hline Yes & 102 & 29 \\
\hline No & 245 & 71 \\
\hline \multicolumn{3}{|c|}{ Self-reported current health condition } \\
\hline Poor & 216 & 56.8 \\
\hline Good & 164 & 48.2 \\
\hline \multicolumn{3}{|c|}{ Payment for the service } \\
\hline Yes & 347 & 91.3 \\
\hline No & 33 & 8.7 \\
\hline \multicolumn{3}{|l|}{ Assigned nurse } \\
\hline Yes & 206 & 54.2 \\
\hline No & 102 & 31.6 \\
\hline Not sure & 54 & 14.2 \\
\hline
\end{tabular}

3.3. Adult Patients' Satisfaction with Nursing Care. Of the total respondents only $52.5 \%$ of patients were found to be satisfied with the nursing care they have received. Furthermore, the amount of freedom on the ward (67\%), nurses' manner in going about their work (62.5\%), nurses' treatment of patients as an individual (59.7\%), and the capabilities of nurses at their job $(58.4 \%)$ were the four top scores whereas amount (46\%) and type (45\%) of information nurses gave to patients about their condition and treatment, the way nurses made patients feel at home (45\%), and nurses' awareness of patient's needs (46\%) were the least scores.

3.4. Factors Associated with Patient Satisfaction with Nursing Care. In bivariate analysis, sex, age, residence, educational status, marital status, admission ward, class of admission, 
payment for the service, self-reported current health condition, and occupation were factors significantly associated with patient satisfaction with nursing care.

However, in the adjusted model, sex, age, self-reported current health condition, admission ward, and class of admission were found to be statistically significantly associated with patient satisfaction with nursing care.

Female patients were about 2 times $(\mathrm{AOR}=2.20,95 \%$ CI: $1.30,3.73)$ more likely to be satisfied with the nursing care as compared to male patients. Patients within the age group of $18-30$ years were almost 5 times (AOR $=4.77,95 \%$ CI: $1.97,11.55)$ more likely to be satisfied with the nursing care as compared to patients above the age of 61. Patients who were admitted in ophthalmology ward were about 10 times $(\mathrm{AOR}=9.99,95 \% \mathrm{CI}: 3.47,28.78)$ more likely to be satisfied as compared to patients admitted in medical ward. Patients admitted in the first class were also more likely ( $\mathrm{AOR}=2.56,95 \% \mathrm{CI}: 1.41,4.67)$ to be satisfied as compared to patients admitted in the second class. In addition, patients who perceive their current health is in good condition were about 2 times $(\mathrm{AOR}=2.07,95 \% \mathrm{CI}: 1.27,3.37)$ more likely to be satisfied as compared to those who perceive their current health status is in poor condition (Table 3 ).

\section{Discussion}

Nursing care is one of the major components of healthcare services. Hence, patients have the right to expect quality of nursing care. Nursing staff are the most numerous professional group and have the greatest contact with patients in comparison with physicians and other healthcare professionals. Therefore, they have significant chance to manipulate patients' attitudes and behaviors' in relation to their treatment, rehabilitation, and recovery process $[5,12]$.

This study revealed that overall satisfaction with nursing care was $52.8 \%$. This finding was lower than studies conducted in Addis Ababa which is 67\% [5] and Malaysia $61.4 \%$ [13]. The possible explanation might be higher number of patients per ward and lower number of nursing staff in the current study as compared to the Addis Ababa study. The difference with Malaysia's study might be due to the inclusiveness of our study; the current study includes medical ward which is usually believed to be the commonest ward with high patient dissatisfaction, while the Malaysia study focuses only on patients in orthopedics ward.

The top aspects of care where patients scored the highest for their satisfaction with nursing care were the amount of freedom on the ward $(67.2 \%)$, nurses' manner in going about their work (62.5\%), nurses' treatment of patients as an individual (59.7\%), and the capabilities of nurses at their job $(58.4 \%)$ whereas amount and type of information nurses gave to patients about their condition and treatment $(46.1 \%)$ and $(44.9 \%)$, respectively, the way nurses made patients feel at home $(45.2 \%)$, and nurses' awareness of patients' needs (45.9\%) were the least scores. These findings are in line with finding of studies conducted in Saudi Arabia, Sri Lanka, Malaysia, and Addis Ababa [5, 9, 13, 14].
This study revealed that female patients were about 2 times more likely to be satisfied with the nursing care as compared to male patients. This finding is consistent with studies done in Saudi Arabia, Jordan, Turkey, and Addis Ababa [5, 1416]. The possible explanation might be that the majority of female patients level of education is lower than males, so their knowledge and expectation towards their needs, rights, and quality of nursing care might be lower than males.

Patients in the age group of 18-30 years were 5 times more likely to be satisfied with the nursing care as compared to patients above the age of 6 . This might be due to the increment of stressful situations like having chronic illness and being widowed in older age and also older patients might need support for their activity of daily living from nurses in relation to this expectation of care from nurses which might be higher in patients above the age of 60 than younger patients.

Patients who were admitted in ophthalmology ward were about 10 times more likely to be satisfied as compared to patients admitted in medical ward. This finding is in line with a study done in Saudi Arabia and Jordan which revealed that those patients were admitted to "other departments" and marked their satisfaction higher than those admitted to either the medical or surgical departments $[14,15]$. The probable explanation for these findings could be that those admitted to ophthalmology ward were able to take care of their activity of daily living and their expectation of care from nurses might be lower than those in medical ward. Whereas patients in medical ward are mostly admitted with more serious conditions, worse prognosis, and being highly exposed to stressful and anxious situation, their perception level might be influenced by "hallo effect" of these factors which made it low.

Class of admission was also one of the factors significantly associated with satisfaction with nursing care. Patients admitted in the first class were 3 times more likely to be satisfied with the nursing care as compared to those in the second class. This finding is in agreement with study done in 12 European countries and Sri Lanka which revealed that better environment has favorable influence on patient satisfaction $[9,17]$. This might be because the number of patients admitted at a time in the first class wards is not more than two and this gives different opportunities to the patient, like to have ease communication with nurses and that first class wards will not be crowded by visitors. This may have positive influence on their satisfaction.

Patients with good self-rating health condition were 2 times more likely to be satisfied as compared to those who were in poor self-rating health status. Similar finding was also reported from three studies done in the USA and the UK which revealed that less sick patients who are in good selfrated health status were highly satisfied [18-21]. The reason for this finding might be due to the fact that having good self-rating health condition and prognosis may contribute to be in a good mood and furthermore their perception might be influenced by the hallo effect of the situation; the reverse might be true for patients whose current health status is in poor situation.

Similar to different studies conducted on the same topic, this study also found out that the length of hospitalization was 
TABLE 3: Bivariate and multivariate analysis of factors associated with adult patients' satisfaction with nursing care.

\begin{tabular}{|c|c|c|c|c|}
\hline \multirow{2}{*}{ Variables } & \multicolumn{2}{|c|}{ Satisfaction } & \multirow{2}{*}{ COR $(95 \%$ CI $)$} & \multirow{2}{*}{$\operatorname{AOR}(95 \% \mathrm{CI})$} \\
\hline & Satisfied & Not satisfied & & \\
\hline \multicolumn{5}{|l|}{ Sex } \\
\hline Male & 64 & 125 & 1 & 1 \\
\hline Female & 102 & 89 & $2.2(1.48,3.39)$ & $2.20(1.30,3.73)^{*}$ \\
\hline \multicolumn{5}{|l|}{ Age in years } \\
\hline $18-30$ & 87 & 55 & $3.7(1.73,7.86)$ & $4.77(1.97,11.55)^{*}$ \\
\hline $31-40$ & 40 & 73 & $1.28(0.59,2.79)$ & \\
\hline $41-50$ & 17 & 37 & $1.07(0.44,2.60)$ & \\
\hline $51-60$ & 10 & 21 & $1.11(0.40,3.05)$ & \\
\hline 61 and above & 12 & 28 & 1 & 1 \\
\hline \multicolumn{5}{|l|}{ Residence } \\
\hline Rural & 86 & 131 & 1 & $* *$ \\
\hline Urban & 80 & 83 & $1.47(0.97,2.21)$ & \\
\hline \multicolumn{5}{|l|}{ Educational status } \\
\hline Illiterate & 73 & 111 & 1 & $* *$ \\
\hline Below 5th grade & 20 & 25 & $1.22(0.63,2.35)$ & \\
\hline 5 th-8th grade & 41 & 53 & $1.18(0.71,1.95)$ & \\
\hline 9th-12th grade & 13 & 16 & $1.24(0.56,2.72)$ & \\
\hline Certificate and above & 19 & 9 & $3.21(1.38,7.48)$ & \\
\hline \multicolumn{5}{|l|}{ Marital status } \\
\hline Single & 60 & 40 & $4.09(1.84,9.09)$ & $* *$ \\
\hline Married & 95 & 144 & $1.79(0.86,3.76)$ & \\
\hline Divorced or widowed & 11 & 30 & 1 & \\
\hline \multicolumn{5}{|l|}{ Occupation } \\
\hline Government employee & 16 & 15 & 1 & \\
\hline Nongovernmental employee & 18 & 14 & $1.20(0.45,3.25)$ & $* *$ \\
\hline Farmer & 49 & 79 & $0.58(0.26,1.28)$ & \\
\hline Merchant & 5 & 12 & $0.39(0.11,1.38)$ & \\
\hline Unemployed & 78 & 94 & $0.77(0.36,1.67)$ & \\
\hline \multicolumn{5}{|l|}{ Admission ward } \\
\hline Medical & 55 & 108 & 1 & 1 \\
\hline Surgical & 56 & 64 & $1.72(1.06,2.79)$ & \\
\hline Orthopedics & 13 & 15 & $1.70(0.76,3.83)$ & \\
\hline Gynecology & 23 & 20 & $2.26(1.14,4.46)$ & \\
\hline Ophthalmology & 19 & 7 & $5.33(2.11,13.45)$ & $9.99(3.46,28.78)^{*}$ \\
\hline \multicolumn{5}{|l|}{ Class of admission } \\
\hline First & 47 & 13 & $2.33(1.40,3.88)$ & $2.56(1.41,4.67)^{*}$ \\
\hline Second & 119 & 183 & 1 & 1 \\
\hline \multicolumn{5}{|l|}{ Self-reported health condition } \\
\hline Poor & 78 & 138 & 1 & 1 \\
\hline Good & 88 & 76 & $2.05(1.35,3.09)$ & $2.07(1.27,3.37)^{*}$ \\
\hline \multicolumn{5}{|l|}{ Payment for the service } \\
\hline Yes & 148 & 199 & 1 & \\
\hline No & 18 & 15 & $1.61(0.79,3.31)$ & \\
\hline
\end{tabular}

${ }^{*}$ Statistically significant at $p$ value $\leq 0.05$

${ }^{* *}$ Statistically not significant in backward stepwise logistic regression. 
not significantly associated with adult patients' satisfaction with nursing care $(p=0.77)[5,13,16]$.

\section{Conclusion}

The proportion of patients satisfied with nursing care was found to be very low. The amount of freedom on the ward, nurses' manner in going about their work, nurses' treatment of patients as an individual, and the capabilities of nurses at their job were the four top scores whereas amount and type of information nurses gave to patients about their condition and treatment, the way nurses made patients feel at home, and nurses' awareness of patients' needs were the least scores.

Being female, age group of 18-30 years, good self-reported current health status, being admitted in ophthalmology ward, and first class of admission were significantly associated with higher patient satisfaction with nursing care.

\section{Competing Interests}

The authors declare that they have no competing interests.

\section{Authors' Contributions}

Kokeb Haile Eyasu, Akilew Awoke Adane, and Mulunesh Abuhay Biwota were involved in the design of the study, data analysis, interpretation of the findings, report writing, and paper preparation. Fisseha Zewdu Amdie and Tesfaye Bisenebit Getahun were involved in the design of the study, analysis and interpretation of the data, and review of the report. All authors read and approved the final paper. All authors contributed equally to this work.

\section{Acknowledgments}

The authors would like to appreciate the Amhara Regional State Health Bureau for all expenses of the research work and all the study participants who voluntarily participated in this study. Furthermore, our gratitude also goes to the NSNS team at the University of Newcastle for their permission to use the NSNS questionnaire in this study.

\section{References}

[1] M. V. Kulkarni, S. Dasgupta, A. R. Deoke, and Nayse, "Study of satisfaction of patients admitted in a tertiary care hospital in Nagpur," National Journal of Community Medicine, vol. 2, no. 1, 2011.

[2] T. Schoenfelder, J. Klewer, and J. Kugler, "Determinants of patient satisfaction: a study among 39 hospitals in an in-patient setting in Germany," International Journal for Quality in Health Care, vol. 23, no. 5, Article ID mzr038, pp. 503-509, 2011.

[3] F. Assefa, A. Mosse, and Y. H. Michael, "Assessment of clients' satisfaction with health service deliveries at jimma university specialized hospital," Ethiopian Journal of Health Sciences, vol. 21, no. 2, pp. 101-109, 2011.
[4] G. U. P. Iloh, J. N. Ofoedu, P. U. Njoku, F. U. Odu, C. V. Ifedigbo, and K. D. Iwuamanam, "Evaluation of patients' satisfaction with quality of care provided at the National Health Insurance Scheme clinic of a tertiary hospital in South-Eastern Nigeria," Nigerian Journal of Clinical Practice, vol. 15, no. 4, pp. 469-474, 2012.

[5] B. Chaka, Adult patient satisfaction with nursing care in Addis Ababa hospitals [M.S. thesis], Department of Community Health, Faculty of medicine, Addis Ababa University, 2005.

[6] E. D. Boudreaux and E. L. O'Hea, "Patient satisfaction in the Emergency Department: a review of the literature and implications for practice," The Journal of Emergency Medicine, vol. 26, no. 1, pp. 13-26, 2004.

[7] S. S. Andaleeb, "Service quality perceptions and patient satisfaction: a study of hospitals in a developing country," Social Science \& Medicine, vol. 52, no. 9, pp. 1359-1370, 2001.

[8] M. Samina, G. J. Qadri, S. A. Tabish, M. Samiya, and R. Riyaz, "Patient's perception of nursing care at a large teaching hospital in India," International Journal of Health Sciences, vol. 2, no. 2, pp. 92-100, 2008.

[9] U. Senarath, N. S. Gunawardena, B. Sebastiampillai et al., "Patient satisfaction with nursing care and related hospital services at the National Hospital of Sri Lanka," Leadership in Health Services, vol. 26, no. 1, pp. 63-77, 2013.

[10] L. H. Thomas, E. McColl, J. Priest, S. Bond, and R. J. Boys, "Newcastle satisfaction with nursing scales: an instrument for quality assessments of nursing care," Quality and Safety in Health Care, vol. 5, no. 2, pp. 67-72, 1996.

[11] L. H. Thomas and S. Bond, "Measuring patients' satisfaction with nursing: 1990-1994," Journal of Advanced Nursing, vol. 23, no. 4, pp. 747-756, 1996.

[12] T. K. Ku and H. Minas, "Development of the Nursing Relationships Scale: a measure of interpersonal approaches in nursing care," International Journal of Mental Health Systems, vol. 4, article 12, 2010.

[13] K. Y. Shirley Teng and S. Norazliah, "Surgical patients' satisfaction of nursing care at the orthopedic wards in Hospital Universiti Sains Malaysia," Health and the Environment Journal, vol. 3, no. 1, pp. 36-43, 2012.

[14] M. Al Momani and H. Al Korashy, "Patient experience of nursing quality in a teaching hospital in Saudi Arabia," Iranian Journal of Public Health, vol. 41, no. 8, pp. 42-49, 2012.

[15] M. A. Alhusban and R. F. Abualrub, "Patient satisfaction with nursing care in Jordan," Journal of Nursing Management, vol. 17, no. 6, pp. 749-758, 2009.

[16] S. Akin and S. Erdogan, "The Turkish version of the Newcastle Satisfaction with Nursing Care Scale used on medical and surgical patients," Journal of Clinical Nursing, vol. 16, no. 4, pp. 646-653, 2007.

[17] L. H. Aiken, W. Sermeus, K. Van Den Heede et al., "Patient safety, satisfaction, and quality of hospital care: cross sectional surveys of nurses and patients in 12 countries in Europe and the United States," British Medical Journal, vol. 344, no. 7851, Article ID e1717, 2012.

[18] C. T. Bacon and B. Mark, "Organizational effects on patient satisfaction in hospital medical-surgical units," The Journal of Nursing Administration, vol. 39, no. 5, pp. 220-227, 2009.

[19] J. L. Jackson, J. Chamberlin, and K. Kroenke, "Predictors of patient satisfaction," Social Science \& Medicine, vol. 52, no. 4, pp. 609-620, 2001. 
[20] J. A. Hall, M. Feldstein, M. D. Fretwell, J. W. Rowe, and A. M. Epstein, "Older patients' health status and satisfaction with medical care in an HMO population," Medical Care, vol. 28, no. 3, pp. 261-270, 1990.

[21] D. L. Patrick, E. Scrivens, and J. R. H. Charlton, "Disability and patient satisfaction with medical care," Medical Care, vol. 21, no. 11, pp. 1062-1075, 1983. 


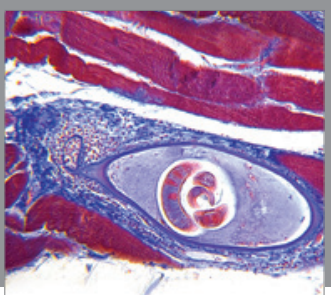

Gastroenterology

Research and Practice
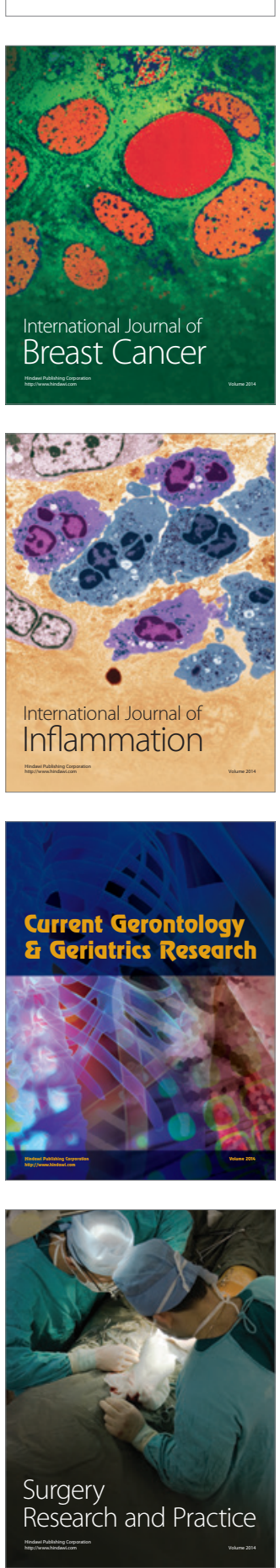

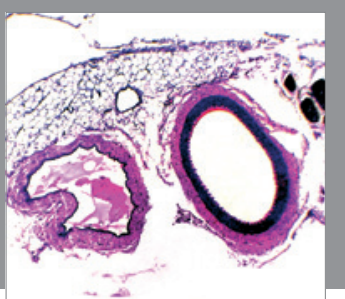

International Journal of Hypertension
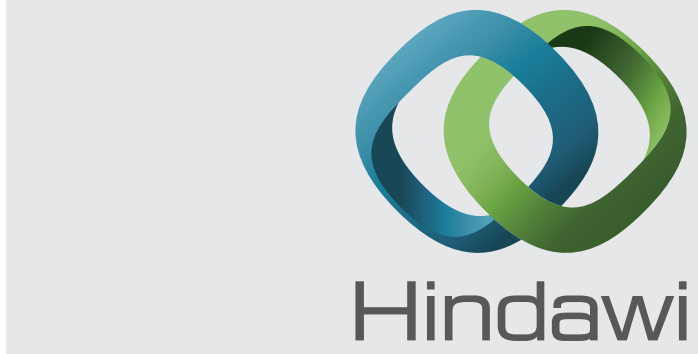

Submit your manuscripts at http://www.hindawi.com
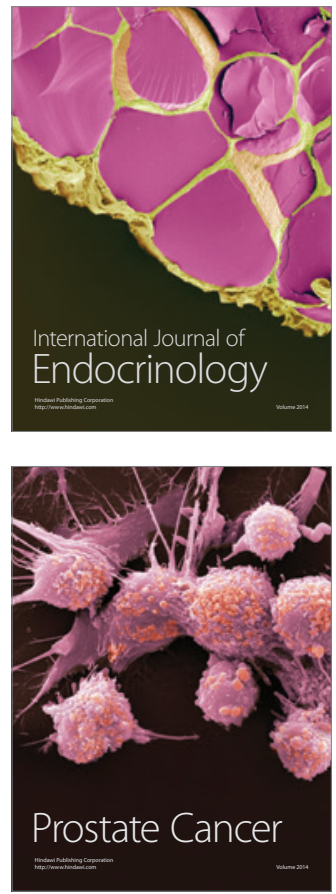

The Scientific World Journal
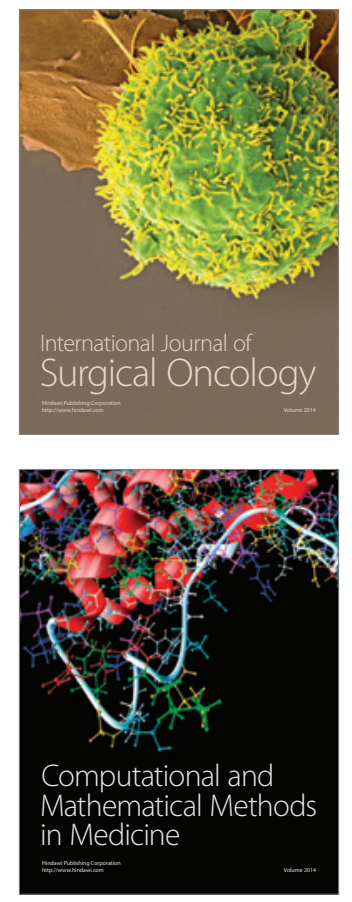
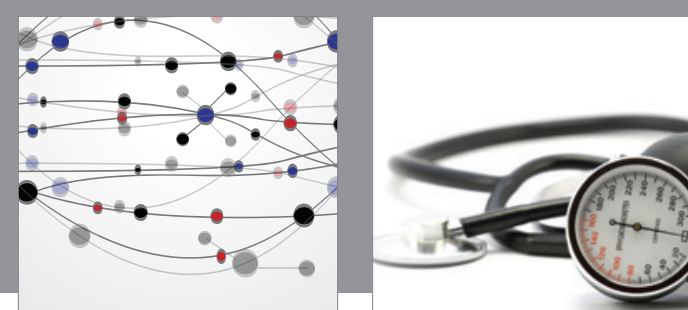

Nursing

Research and Practice

Research and Practice
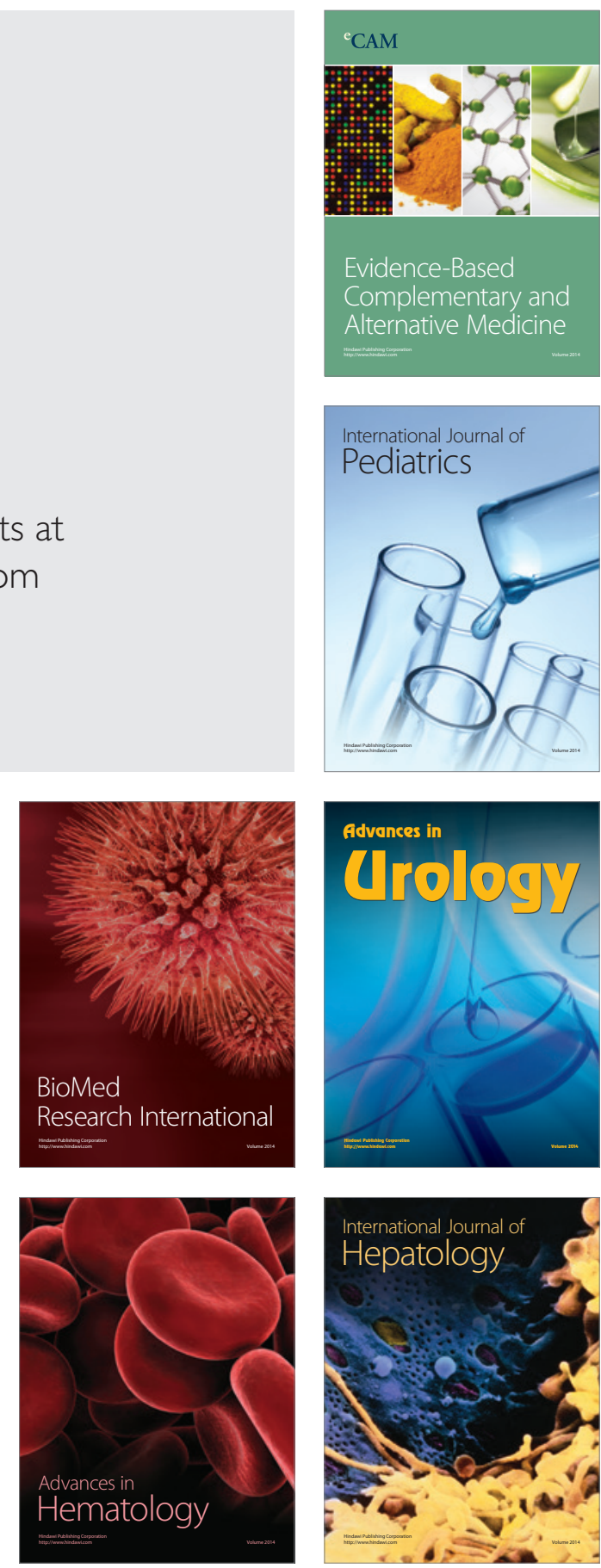
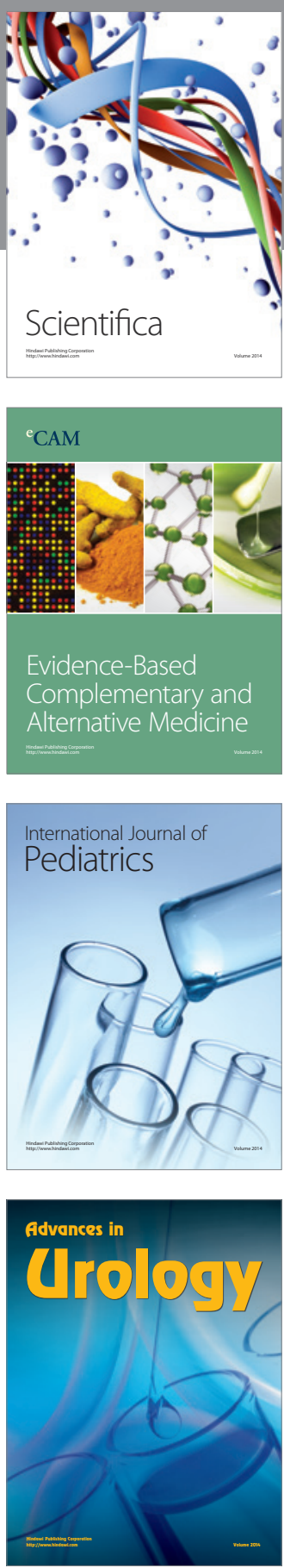

Scientifica

Evidence-Based

Complementary and

Alternative Medicine

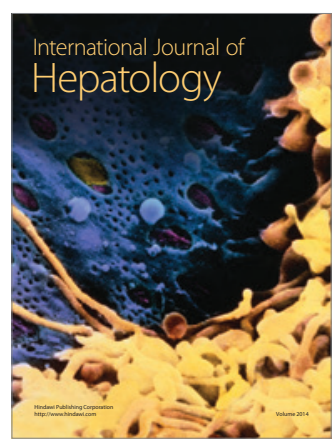

